\title{
Условные конструкции с деепричастием и союзными словами в калмыцком и бурятском языках
}

\section{Влада Вячеславовна Баранова ${ }^{1}$}

${ }^{1}$ Национальный исследовательский университет «Высшая школа экономики» (д. 55, корп. 2, ул. Седова, 192148 Санкт-Петербург, Российская Федерация); Институт лингвистических исследований РАН (д. 9, Тучков переулок, 199053 Санкт-Петербург, Российская Федерация)

канд. ист. наук, доцент, научный сотрудник

iD 0000-0003-1642-4003. E-mail: vbaranova@hse.ru

(C) КалмНЦ РАН, 2020

(C) Баранова В. В., 2020

Аннотация. Введение. В статье рассматриваются разные типы условных конструкций в бурятском и калмыцком языках, выраженные условным деепричастием или с помощью союзных слов. Цель статьи - рассмотреть выражение условных значений в калмыцком и бурятском языках. В работе анализируется, как соотносятся условные предложения, маркированные деепричастием на -хла или -bol и союзные способы выражения временных и условных значений в калмыцком языке; для сравнения привлекаются также данные бурятского и халхасского языков. Материалом послужили как полевые записи автора (небольшой устный корпус, цитаты из которого приводятся без указания на источник), так и корпуса калмыцкого и бурятского языков (Калмыцкий корпус, далее - КК, и Бурятский корпус, далее - БК). Результаты. Условные конструкции в монгольских языках традиционно выражаются нефинитной формой условного деепричастия (форма на -bal в халха-монгольском и бурятском в калмыцком языке была вытеснена новой формой условного деепричастия на -хла). Наряду с этим способом выражения условного значения возникают модели, похожие на союзное сложное предложение с союзами хэрбээ в бурятском и кемр в калмыцком, стоящими в начале клаузы. Эти относительно новые стратегии выражения условного значения используют монгольские элементы, но синтаксически напоминают языки с союзными стратегиями сложного предложения, в частности русский. В центре внимания находится вопрос о развитии союзного оформления: можно ли интерпретировать это как контактное влияние русского языка? Союзная и деепричастная стратегия выражения условного значения используются одновременно: во многих монгольских языках есть больше одного способа выразить условное значение. На материале корпусных данных рассматривается частотность разных способов оформления условных конструкций в бурятском и калмыцком языках. Развитие условных союзов хэрбээ в бурятском и кемр в калмыцком может быть интерпретировано как контактное явление. Однако грамматикализация условного деепричастия гихлә в показатель условной конструкции 
представляется результатом внутреннего развития, характерного для грамматикализованного глагола ги- 'говорить' в калмыцком и для семантического развития дицендиальных глаголов в языках мира.

Ключевые слова: деепричастие, калмыцкий язык, бурятский язык, условная конструкция, союз, интерференция

Благодарность. Я благодарю Б. Д. Бальжинимаеву за комментарии к бурятским данным. Исследование выполнено при финансовой поддержке РФФИ в рамках научного проекта № 19-512-44006 «Взаимодействие языков в поликультурном пространстве на материале монгольских языков: сравнительный анализ калмыцкого языка, языка ойратов Монголии и бурятского языка». Материалы статьи апробированы на Международной научной онлайн-конференции «Монголоведение в начале XXI в.: современное состояние и перспективы развития - II», проведенной при финансовой поддержке РФФИ (проект № 20-09-22004) и частичной поддержке гранта Правительства РФ (№ 075-152019-1879).

Для цитирования: Баранова В. В. Условные конструкции с деепричастием и союзными словами в калмыцком и бурятском языках // Монголоведение. 2020. Т. 12. № 4. С. 635-643. DOI: 10.22162/2500-1523-2020-4-635-643

UDC 811.512 .3

DOI: $10.22162 / 2500-1523-2020-4-635-643$

\section{Kalmyk and Buryat Languages: Conditional Constructs with Converbs and Conjunctions}

\section{Vlada V. Baranova ${ }^{1}$}

${ }^{1}$ National Research University Higher School of Economics (55/2, Sedov St., St. Petersburg 192148, Russian Federation); Institute for Linguistic Studies of the RAS (9, Tuchkov Lane, St. Petersburg 199053, Russian Federation)

Cand. Sc. (History), Associate Professor, Research Associate

iD 0000-0003-1642-4003. E-mail: vbaranova@hse.ru

(C) KalmSC RAS, 2020

(C) Baranova V. V., 2020

Abstract. Introduction. The paper deals with different conditional constructions in Buryat and Kalmyk. Traditionally, the main way to express the conditional meaning in Mongolic languages is a non-finite clause with a converb (there are the conditional form on -bal in Buryat and Khalkha and new marker -xla in Kalmyk). Alongside with it, there are some new conditional constructions with connectives, with conjunction-like markers herbee in Buryat and Khalkha and kemor in Kalmyk co-occurring with a form of conditional converb. The language contact approach presupposes that connectives as well as a structural pattern with a conjunction are frequently borrowed from dominant languages. Thus, the research question of the paper is how to explain the new conditional construction. Results. In particular, the paper discusses the distribution of different types of conditional construction according to the data from Buryat and Kalmyk corpora. It suggests that conjunction-like markers herbee 'if' in Buryat and kemər 'if' in Kalmyk may be viewed as grammatical interference from Russian. Nevertheless, the form of conditional converb gixlä developing to a connective in Kalmyk is 
grammaticalized among other forms of the verb gi- 'say' and its grammaticalization of a verb of saying to marker of a conditional clause is frequent cross-linguistically.

Keywords: converb, Kalmyk, Buryat, conditional clause, conjunction, grammatical interference

Acknowledgements. The author extends gratitude to Bayarma Balzhinimaeva for most precious comments on Buryat-language data. The reported study was funded by RFBR, project no. 19-512-44006 'Language Contact in Multicultural Contexts: The Comparative Analysis of Mongolic Languages (Case Studies of Kalmyk, Oirat Mongolian and Buryat Languages)'. The article was presented at the International scientific online conference 'Mongolian Studies at the Beginning of the $21^{\text {st }}$ Century: Current State and Development Prospects - II' funded by RFBR (project no. 20-09-22004) and Government of Russia (grant no. 075-15-2019-1879).

For citation: Baranova V. V. Kalmyk and Buryat Languages: Conditional Constructs with Converbs and Conjunctions. Mongolian Studies (Elista). 2020. Vol. 12. No. 4. Pp. 635-643. (In Russ.). DOI: 10.22162/2500-1523-2020-4-635-643

\section{Введение}

Монгольские языки выражают отношения между частями сложного предложения с помощью нефинитных форм, передающих целевые, условные, временные (предшествование одного действия другому) и другие значения. Большинство таких единиц - деепричастия (конвербы). Однако наряду с такой системой организации сложного предложения в некоторых монгольских языках существуют и союзные стратегии, в большинстве случаев более периферийные (см. подробное описание союзных стратегий в калмыцком языке [Пюрбеев 2010]). Распространенное суждение о развитии союзных стратегий в языках Евразии предполагает, что под влиянием контактов с языками, в которых части сложного предложения соотносятся с помощью союзов, союзные стратегии развились и в языках, которым не были свойственны.

С одной стороны, союзы, как и дискурсивные элементы, относятся к числу единиц, которые достаточно легко заимствуются или включаются из доминирующего языка при переключении кодов [Matras 2009: 157]. Достаточно часто встречаются прямые заимствования русских союзов в контактирующие языки: например, причинный союз потому что в казахском языке или условный союз рас в татарском (из русского разговорного показателя раз: раз ты пришел, давай чай пить) [Muhamedowa 2009: 337]. Засвидетельствованы случаи возникновения смешанных форм, например в коми-ижемском плеонастическая форма условного союза jesl' $i-k o ̈$ возникла из заимствованного русского если и исконной коми частицы kӧ 'если’ [Leinonen 2009: 325-326]. Нередко эти заимствования сосуществуют с исходными способами выражения отношений внутри сложного предложения, как в восточно-хантыйском: используются как русская условная конструкция если... то, так и традиционный бессоюзный способ с условной формой глагола [Potanina, Filchenko 2016: 34]. С другой стороны, распространённым является заимствование модели союзного сложного предложения, когда под влиянием доминирующего языка, уже существующая единица развивает новое значение или расширяет употребление (patternborrowing в терминах [Matras, Sakel 2007]). 


\section{Монголоведение • Mongolian Studies • 2020 ๑ T. 12 • № 4}

Прямое заимствование материального показателя союза не свойственно монгольским языкам (отдельные случаи можно рассматривать как примеры переключения кодов или спонтанного заимствования в речи билингвов). Однако существует ряд единиц, чье развитие отчасти напоминает союзы в индоевропейских языках. Вопрос о том, является ли это внутренним развитием или контактно-обусловленной грамматикализацией, должен решаться применительно к конкретным показателям, поскольку союзы и союзные слова - гетерогенная группа, складывающаяся как из исконных непроизводных единиц, так и заимствований разного времени или грамматикализовавшихся деепричастий, послелогов и др. В данной статье рассматривается выражение условных значений в некоторых монгольских языках. В частности, будет рассмотрено, как соотносятся условные предложения, маркированные деепричастием на -хла или -bol и союзные способы выражения временных и условных значений в калмыцком языке; для сравнения будут привлечены также данные бурятского и халхасского языков. Материалом послужили как полевые записи автора (небольшой устный корпус, цитаты из которого приводятся без указания на источник), так и корпуса калмыцкого и бурятского языков (Калмыцкий корпус, далее - КК, и Бурятский корпус, далее - БК).

\section{Условное деепричастие}

В халха-монгольском и бурятском форма условного деепричастия - $b A l$ возникла из старой формы -basu. В калмыцком языке возникла новая форма условного деепричастия на -хла. Показатель -хла относится к числу вторичных деепричастий, возникших из сочетания застывших падежных форм с причастием на $-x$ (целевое деепричастие на $-x a p<x$-ap причастие будущего времени с орудным падежом, деепричастие на -хл $a<-x-л a$, форма соединительного падежа будущего времени). Как отмечает А. Ракош, форма Adverbium Conditionale на $-w l$, использовавшаяся в письменном ойратском, редко встречается в современных ойратских диалектах, а в условных конструкциях используются формы Adverbium Successivi на -xlā / xlä и -xlārn / xlärn, которые обозначали действие, начавшееся сразу после окончания другого, однако также могли выражать и условное значение [Rákos 2015: 92-93]. В современном калмыцком представлены разные формы этого деепричастия, см. подробнее [Баранова 2019] о формах -хларнь, -хлаг; в частности предложена трактовка показателя -хлаг как сочетания аффикса условного деепричастия и винительного падежа.

В разных монгольских языках условное деепричастие используется в условной конструкции и других адвербиальных зависимых, прежде всего временных. Порядок клауз при этом обычно предполагает предшествование условной конструкции главной. Во многих монгольских языках формы условного деепричастия развили те или иные модальные значения, например, в калмыцком форма болхла используется для выражения ирреалиса. Подобное развитие можно объяснить эллипсисом главного предложения с финитной формой (инсубординацией) [Ямакоши 2017: 291-292].

Другой круг значений связан с топикальным статусом условных конструкций. В частности, в халха-монгольском показатель топика $b o l$ возник из стя- 
женной формы условного деепричастия глагола 'стать'. В калмыцком языке лексикализовались формы условного деепричастия от глаголов-местоимений 'делать так' (тиигхлә, ииххл), глагола 'стать' (болхла) и 'говорить' (гихлә), в бурятском им примерно соответствуют формы тиигэбэл, болбол. Они используются в качестве маркеров хезитатиции, в качестве эмфатической конструкции для выделения какого-то слова и топикализации с болхла (в устном калмыцком часто в форме -хлаг: болхлаг, тиигхләг, см. подробнее [Баранова 2019]).
1) Ekam
bol-xla
jun $u j-d \partial g$,
$u j-d \partial g$
bilä
мама
стать-CV.SUCC что шить- РC.НАB
шить-РС.НАВ бЫть.REM
'Мама же швея, была швеей'.

\section{Союзная стратегия в монгольских языках и грамматикализация дее- причастий}

Союзная стратегия оформления условной конструкции слабо грамматикализована в монгольских языках: в халхасском «союзообразный» маркер хеreb дополнительно выражает условные отношения вместе с деепричастием на - bal, т. е. xereb еще нельзя трактовать как союз в полном смысле [Janhunen 2012: 287]. В бурятском отмечается сходное развитие показателя хэрбээ в условный союз, но интересно соотношение лексического и морфологического способов выражения условной семантики.

Данные корпуса бурятского языка показывают, что выражение условного значения возможно как только формой условного деепричастия -бал / -бэл / -бол, так и с помощью двойного маркирования. Обычно один элемент этого расщепленного кодирования условных конструкций союзообразный показатель хэрбээ в сочетании с формой условного деепричастия -бал, как в примере (2); с постпозитивной частицей haa (3), в одиночном употреблении маркирующей уступительные конструкции; с частицей бол $(<$ bolbol), возникшей из формы условного деепричастия вспомогательного глагола bol- 'стать' и служащей маркером топика (4).
2) Хэрбээ
гар-ай
хүдэл-бэл,
сэдьхэл-шье хүдэл-нэ
если рука-GEN
двигаться-CVB.COND
мысль-PCL двигаться- PRS

'Если руки заняты, то и мысль работает'.

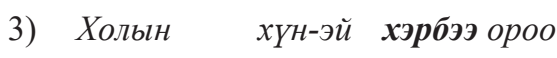

[М. Батоин. Буддын суртал (2007), БК] дальний человек- GEN если

haa, эшхэбтэр шэнги.

'Если зайдет человек, прибывший издалека, неудобно'.

входить PCL.CONC неудобно словно

[Ч. Цыдендамбаев. Банзарай хүбүүн Доржо (1953), БК]

4) Хэрбээ зарим гэр-нүүд-эйнь тооно-ор бүүдэгэрхэн утаан-ай гараа-гүй бол, если некоторый дом-PL дымовое.отверстие- INS-GEN-P3 неясный дым-GEN выходить- NEG TOP

тэдэниие холоһоохараха-да обёор-хоор бэшэ.

3. PL издалека смотреть-CVB замечать-CVB.PURP NEG

'Если не будет видно еле заметного дыма из трубы, увидеть издалека невозможно'.

[Б. Санжин, Б. Дандарон. Заяанай зам (1966), БК] 


\section{Монголоведение • Mongolian Studies • 2020 ๑ T. 12 • № 4}

В примерах (2) и (3), по оценке носителей языка, показатель хэрбээ может быть и опущен, тогда как в примере (4) для передачи уступительного значения недостаточно топикальной частицы бол. Можно видеть, как происходит грамматикализация показателя хэрбээ в условный союз или союзообразный показатель. Во-первых, в большинстве случаев порядок слов соответствует положению союза в индоевропейских языках, в начале клаузы, хотя возможен и другой порядок слов, как в примере (3). Во-вторых, формы с двойным маркированием с условным деепричастием составляют лишь небольшую часть употреблений показателя хэрбээ в корпусе: из 825 случаев употребления показателя хэрбээ в БК условное деепричастие в той же клаузе находится лишь в 54 случаях. Наиболее распространенным случаем употребления хэрбээ является сочетание хэрбээ... haa $(\mathrm{N}=406)$, часто переводимое как парный союз если... $m o$, без дополнительного морфологического кодирования условной конструкции.

В калмыцком языке нет такого однозначного развития союзной стратегии на основе одного показателя. Г. Ц. Пюрбеев описывает несколько способов союзного выражения условных значений, прежде всего союзы кемр и кемржсәнд, а также «дицендиальное союзное слово гихлд, расчленённые союзные сочетания кемр... гихлә 'коль... если', а также малоупотребительное сочетание гисн хөөн [Пюрбеев 2010: 235].

Все эти способы, по экспедиционным данным, крайне мало представлены в устной речи. В письменной они также не слишком частотны; относительно регулярно используется только союз кемр в условной конструкции с двойным маркированием с показателем условного деепричастия (174 примера в корпусе).

5) Кемр бүркг өдри-г сөө-д тоол-хла, сөньолн бол-жс һар-на если пасмурный день-АCC ночь-DAT считать-CVB.SUCC ночь много стать-CVB.IPFV выходит-PRS

'Если пасмурные дни принимать за ночи, то ночей оказывается больше'.

[Пюрбеев 2010: 192]

Важно отметить, что эти способы организованы по-разному: если союзы кемр и кемржсәнә находятся в начале зависимого предложения и сочетаются с формой условного деепричастия, то развитие показателя гихлә как маркера условной констркуции располагается в конце клаузы, что свойственно для условного деепричастия: Очевидно, что форма гихлә грамматикализована, как в примере (6), однако в некоторых случаях может быть переведена буквально как условное деепричастие.

6) Кемр хаалһ-ас хажчи-й ги-хло, белкүсцуә-һән көр-т булх-гд-на если дорога-ABL отступать-HOR говорить-CVB.SUCC до.пояса- P.REFL сугроб-DAT закапывать-PASS-PRS 'Как только надумаешь свернуть с дороги, сразу же по пояс проваливаешься в снег'. 
Формы условного деепричастия в сочетании с вопросительными словами, образованными в свою очередь формами разделительного деепричастия, образуют союзообразные конструкции со значением уже не условного, а причинного союза. Наиболее распространённым является сочетание юңгад гихлд, другое сочетание яһад гихль. Следует отметить, что не все носители языка одинаково оценивают эти конструкции: некоторые избегают их использования из стилистических соображений.

Лексикализация выражений юңзад гихлә и яһад гихлә показывает переход от биклаузальной структуры (когда юңзад гихлә интерпретировалось как придаточное, соотносящееся с главным предложением) к моноклаузальной. Выражение собственного подлежащего зависимой клаузы невозможно, но встречается промежуточное употребление, близкое к функциям вставной конструкции, как в примере (7).

7) Я̆ад ги-хлә, чи дегәд тагчгар ишк-жс мөлк-нд-ч, гижс туула хәрү өгв что сказать, 2SG.NOM потом тихо наступать-CVB.IPF ползти-PRS-2SG заяц ответ дать

'Что (можно) сказать, ты подползаешь незаметно - ответил Заяц'.

[Хальмг үнн, 2006-05-04, КК]

В небольшом корпусе калмыцкого языка (КК) из 851 случая употребления формы условного деепричастия от глагола ги- 'говорить', гихлә, большинство составляют юңзад гихлә (N=551) и 79 употреблений яһад гихлд.

Союзообразный показатель юңзад гихлә стоит при этом в начале предложения и обычно в зависимой клаузе, как в примере (7).
7) juygad gi-xlä
$\check{c} i$
xal'mag kel-n
durl-ad (...)
почему говорить-CVB.SUCC $\quad$ 2SG.NOM калмыцкий язык-EXT любить-CVB.ANT
'Потому что ты полюбила калмыцкий язык....'

Однако в речи некоторых носителей возникают, вероятно, в качестве интерференции русской модели придаточных предложений с союзом потому, конструкции, в которых юңзад гихлә оформляет вторую часть с финитной формой, что естественно для русского языка, но не свойственно монгольским языкам.

\section{Заключение}

Выше кратко рассмотрены соотношения условных деепричастных конструкций в калмыцком и бурятском языках и маркирование условных конструкций союзными или союзообразными показателями. Развитие показателя хэрбээ в бурятском (и, вероятно, халха-монгольском) и союза кемр в калмыцком сходно с индоевропейскими структурами условных предложений и может быть интерпретировано как контактное явление. Однако грамматикализация условного деепричастия гихлә в показатель условной конструкции представляется результатом внутреннего развития топикальной конструкции с условным деепричастием десемантизированных глаголов. Развитие союзов, в том числе с условным значением, - характерное направление грамматикализации для глагола ГОВОРИТЬ в разных языках (ср. русскую противительную конструкцию не говоря уже о том... ). Одновременно с этим сочетания с гихлә 


\section{Монголоведение • Mongolian Studies • 2020 ๑ T. 12 • № 4}

(юңзад гихлә и др.) развиваются в союзные слова, стоящие в начале предложения, что также сходно с моделями союзного предложения в русском языке. Нужно отметить, что в речи некоторых носителей порядок клауз с юңзад гихлә копирует русские модели сложного предложения.

\section{Сокращения}

2, 3 - 2, 3 лицо; ABL — аблатив; ACC — винительный падеж; CVB.ANT — разделительное деепричастие; CVB.COND - условное деепричастие; CVB. IPFV - соединительное деепричастие; CVB.SUCC - последовательное или условное деепричастие; DAT - дательный падеж; HOR — гортатив, желательное наклонение; NEG — отрицание; P — личный посессивный показатель; PCL — частица; РС.НАВ - хабитуальное («многократное») причастие; PC.PST причастие прошедшего времени; PL — множественное число; PRS — настоящее время; PURP - деепричастие цели; REM — отдаленное прошедшее время; SG - единственное число; ТОР — показатель топика.

\section{Литература}

Баранова 2019 - Баранова В. В. Условное деепричастие на -хла в калмыцком языке // Монгол-Орос хэл шинжлэлийн түүвэр / ред. Г. Билгуудэй и др. Улаанбаатар, 2018. С. 392-405.

БК - Корпус бурятского языка (http://web-corpora.net/BuryatCorpus/search/).

КК - Корпус калмыцкого языка (http://web-corpora.net/KalmykCorpus/search).

Пюрбеев 2010 - Пюрбеев Г. Ц. Грамматика калмыцкого языка. Синтаксис. 2-е изд., перераб. Элиста: КИГИ РАН, 2010. 299 с.

Ямакоши 2017 - Ямакоши Я. Монгол төрөл хэлнүүдийн «insubordination» (гишүү бус огүүлбэр) // Монгол судлал ба тогвортой хөгжил. Улаанбаатар, 2017. С. 289-292.

Janhunen 2012 - Janhunen J. Mongolian. Amsterdam: John Benjamins, 2012. 320 p.

Leinonen 2009 - Leinonen M. Russian influence on the Ižma Komi dialect // International Journal of Bilingualism, 2009. Vol. 13. No. 3. P. 309-329.

Matras 2009 - Matras Y. Language contact. Cambridge: Cambridge University Press, 2009. $366 \mathrm{p}$.

Matras, Sakel 2007 - Grammatical borrowing in cross-linguistic perspective / ed. by Y. Matras. \& J. Sakel. Berlin: Mouton de Gruyter, 2007. 610 p.

Muhamedowa 2009 - Muhamedowa R. Russian Conjunctions in the Speech of Kazakhs // The International Journal of Bilingualism. Vol. 13. No. 3. 2009. P. 331-356.

Potanina, Filchenko 2016 - Potanina O., Filchenko A. Russian Contact-Induced Innovations in Eastern Khanty // Томский журнал лингвистических и антропологических исследований. 2016. Vol. 12. No. 2. Р. 27-39.

Rákos 2015 - Rákos A. Synchronic and Diachronic Comparative Analysis of the Oirad Dialects. Doktori Disszertáció. Budapest: Eötvös Loránd University, 2015. 167 p.

\section{References}

Baranova V. V. Conditional converbs with -xla in the Kalmyk language. In: Bilguudey G. et al. (eds.) Mongolian-Russian Linguistics. Collected Papers. Ulaanbaatar, 2018. Pp. 392405. (In Russ.)

Corpus of the Buryat Language. Available at: http://web-corpora.net/BuryatCorpus/search/ (In Bur.)

Corpus of the Kalmyk Language. Available at: http://web-corpora.net/KalmykCorpus/search (In Kalm.) 
Janhunen J. Mongolian. Amsterdam: John Benjamins, 2012. 320 p. (In Eng.)

Leinonen M. Russian influence on the Ižma Komi dialect. International Journal of Bilingualism. 2009. Vol. 13. No. 3. Pp. 309-329. (In Eng.)

Matras Y. Language contact. Cambridge: Cambridge University Press, 2009. 366 p. (In Eng.)

Matras Y., Sakel J. (eds.) Grammatical Borrowing in Cross-Linguistic Perspective. Berlin: Mouton de Gruyter, 2007. 610 p. (In Eng.)

Muhamedowa R. Russian conjunctions in the speech of Kazakhs. International Journal of Bilingualism. 2009. Vol. 13. No. 3. Pp. 331-356. (In Eng.)

Potanina O., Filchenko A. Russian contact-induced innovations in Eastern Khanty. Tomsk Journal of Linguistics and Anthropology. 2016. Vol. 12. No. 2. Pp. 27-39. (In Eng.)

Pyurbeev G. Ts. Kalmyk Grammar: Syntax. $2^{\text {nd }}$ ed., rev. Elista: Kalmyk Humanities Research Institute (RAS), 2010. 299 p. (In Russ.)

Rákos A. Synchronic and Diachronic Comparative Analysis of the Oirad Dialects. Budapest: Eötvös Loránd University, 2015. 167 p. (In Eng.)

Yamakoshi Ya. 'Insubordination' in Mongolic languages. In: Mongolian Studies and Sustainable Development. Ulaanbaatar, 2017. Pp. 289-292. (In Mong.) 